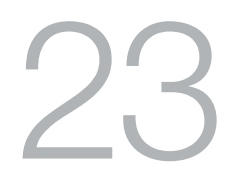

\title{
Effective Law for Rural Environmental Governance: Meta-Governance Reform and Farm Stewardship
}

\section{Paul Martin, Amanda Kennedy and Jacqueline Williams}

\section{Introduction}

Protection of biodiversity is principally concerned with the governance of rural lands and surface waters. This is because intact biodiversity is most likely to be found in rural areas that have not been converted to industry or urbanisation. But Australia's biodiversity performance is not heartening, despite the existence of many legal and other instruments and programs. ${ }^{2}$ Threatened species in particular have suffered, with 50 animal species and 48 plant species listed as extinct since the passage of the Environment

2 Department of the Environment, 'Australia's Fifth National Report under the Convention on Biological Diversity' (Australian Government, 2014); Department of the Environment, 'State of the Environment Report 2011' (Australian Government, 2011); IISD Reporting Services, OAS, UNEP Increase Cooperation on Environmental Rule of Law (19 November 2014), sd.iisd.org/news/oas-unepincrease-cooperation-on-environmental-rule-of-law/. 
Protection and Biodiversity Conservation Act 1999 (EPBC Act). ${ }^{3}$ Public funding for biodiversity protection is also insufficient and under threat, ${ }^{4}$ while the complexity of the biodiversity challenge is increasing.

Biodiversity decline has continued despite the proliferation of governance programs and laws, suggesting a failure of implementation. ${ }^{5}$ There is support for this hypothesis. ${ }^{6}$ The Secretary General of the Chief of Staff of the Organization of American States has joined a growing cohort highlighting the implementation failings of environmental governance, calling the implementation of environmental law 'the greatest challenge of our century. ${ }^{7}$ Traditional legal instruments for rural environmental governance, and scholarly discussions of the issues, tend to emphasise individual stewardship by private landholders. They also tend to focus on specific governance instruments, rather than the determinants of the performance of the governance system as a whole. Many fundamental strategic challenges are overlooked. Current approaches do not generate the whole-of-landscape, socioeconomically realistic responses that are needed for increasingly complex systemic problems. This complexity stems from factors including diverse land uses and ownership; fundamental disagreements about the objectives and methods of protection and restoration; the proliferation of governance interventions; and the insufficient economic capacity of farmers and other rural people to implement law, compared to their urban counterparts.

In this chapter we consider some less obvious systemic challenges and opportunities to overcome issues that limit conventional environmental governance approaches. We then propose some approaches to reform meta-governance processes - that is, to the governance of governance

3 Australian Bureau of Statistics, 1301.0 - Year Book Australia, 2009-10: Australia's Biodiversity (ABS, 2010), www.abs.gov.au/ausstats/abs@.nsf/Previousproducts/1301.0Feature\%20Article12009 $\% \mathrm{E} \% 80 \% 9310$ ? opendocument $\&$ tabname=Summary $\&$ prodno $=1301.0 \&$ issue $=2009 \% 9610 \&$ num $=\&$ view $=$.

4 The Australian budget released in May 2014 included significant cuts of funding to Landcare and Cooperative Research Centres, and the abolishment of the National Water Commission and the Biodiversity Fund. This was after significant cuts in 2013 to biodiversity and carbon farming futures programs for rural landholders.

5 Euan Ritchie et al, 'Continental-Scale Governance Failure Will Hasten Loss of Australia's Biodiversity' (2013) 27(6) Conservation Biology 1133; Department of the Environment, 'Australia's Fifth National Report under the Convention on Biological Diversity' (Australian Government, 2014).

6 Ibid.

7 Organization of American States Secretary General Hugo De Zela, on the signing of the Agreement on Environmental Rule of Law and Sustainable Development, 19 November 2014, Washington DC; see IISD Reporting Services, above n 2. 
frameworks themselves. ${ }^{8}$ These proposals concern the arrangements used to create, review, reform and implement governance instruments, rather than the content of legal instruments. It is at this level that the greatest challenges to legal effectiveness exist, and the most significant innovations are needed. The major innovation we propose is not a new instrument, though this will also be needed. Rather, we suggest reforms to meta-governance processes. These changes will be needed to ensure that instrumental innovations (i) can be effectively implemented by the people who are required to take action, (ii) are efficient in how they operate at the front line, and (iii) fairly allocate the costs and benefits of protecting biodiversity and of the governance system itself.

\section{Conditions for Effective Environmental Law}

We begin with a simple question: what are the conditions under which an environmental law is likely to be effective? For the past decade our research team has concentrated on rural legal governance as a systems issue. Our research suggests that there are three necessary conditions for the success of governance instruments:

1. Reliable policy concepts allow governance interventions precisely to address the problem. A misguided or incomplete understanding of the problem will increase the risk of failure.

2. Efficient and effective instrument design creates effective interventions with a feasible strategy for implementation. This involves choosing the most appropriate instrument - regulation, market or social intervention - to encourage the behavioural change required, depending upon the characteristics of those being regulated, and the available resources and commitment to implementation. ${ }^{10}$

8 See Jan Kooiman and Svein Jentoft, 'Meta-governance: Values, Norms and Principles, and the Making of Hard Choices' (2009) 87(4) Public Administration 818; Stephen Bell and Alex Park, 'The Problematic Metagovernance of Networks: Water Reform in New South Wales' (2006) 26(1) Journal of Public Policy 63; Bob Jessop, 'The Rise of Governance and the Risk of Failure: The Case of Economic Development' (1998) 50(155) International Social Science Journal 29; Michael Lockwood et al, 'Multi-level Environmental Governance: Lessons from Australian Natural Resource Management' (2009) 40(2) Australian Geographer 169; Louis Meuleman, Public Management and the Metagovernance of Hierarchies, Networks and Markets: The Feasibility of Designing and Managing Governance Style Combinations (Springer Science \& Business Media, 2008).

9 Paul Martin and Jacqueline Williams, 'Policy Risk Assessment' (CRC for Irrigation Futures Technical Report Series No 03/10, 2010).

10 Paul Martin and Jacqueline Williams, 'Next Generation Rural Natural Resource Governance: A Careful Diagnosis' in Volker Mauerhofer (ed), Legal Aspects of Sustainable Development (Springer International Publishing, 2016) 607. 
3. Community support makes the success of environmental law more likely. The intervention (the law) must reasonably align with selfinterest to encourage desired action (or at least not generate negative reaction). There should also be a social perception that the intervention is justified and fair, and that the implementing body has integrity. A perception that an intervention is impractical or unfair can legitimate non-compliance and deprive the intervention of its social supports. ${ }^{11}$

There are many aspects of the current system that do not adequately satisfy these preconditions for performance. Our research suggests that while positive farmer attitudes are always important, new challenges and socioeconomic and natural resource management realities mean that many conventional governance solutions face serious challenges of feasibility, and risk undesirable spillovers. We argue that significant change in how we approach the design and implementation of rural governance is needed if we are to improve biodiversity outcomes. Australia needs a far more systematic approach to creating, implementing and evaluating the instruments and strategies of rural governance.

\section{Challenges to Achieving Effective Rural Environmental Governance}

Environmental governance involves instruments to control, direct, and motivate behaviour to achieve public goals for the ever-changing state of the environment. Success requires a good 'fit' between the instruments, the context, resources and the capabilities and commitment of those charged with implementation. ${ }^{12}$ There are many aspects of the current system that do not adequately satisfy the necessary conditions for governance success.

Many conventional approaches to rural governance reflect a view of land use being principally agricultural, mainly broad-acre cropping and animal production. Readily identifiable on-farm environmental problems include soil erosion, land-clearing, wasteful use of water, excessive

11 Paul Martin, Jacqueline Williams and Christopher Stone, 'Transaction Costs and Water Reform: The Devils Hiding in the Details' (Cooperative Research Centre for Irrigation Futures Technical Report No 08/08, 2008).

12 Paul Martin and Donna Craig, 'Accelerating the Evolution of Environmental Law through Continuous Learning from Applied Experience' in Paul Martin and Amanda Kennedy (eds), Implementing Environmental Law (Edward Elgar, 2015) 27. 
chemical use and habitat destruction. The natural focus of governance is, therefore, on farmer stewardship within individual estates. Examples of egregious irresponsibility prosecuted or reported in the media lead many in society to associate stewardship failure with mala fides; however, this assumption overlooks the contextual socioeconomic factors that underlie environmental problems. ${ }^{13}$

As many farmers argue, farm financial vulnerability and volatility, limited human resources and the relatively poor socioeconomic status of rural communities create conditions in which it is not feasible for them to meet the stewardship expectations that the law and (urban-based) public opinion place upon them. As a percentage of total population, Australia's rural population is a little over 10 per cent, and spread thinly over an extensive landscape. ${ }^{14}$ Physical distance - both between citizens within rural communities, and between rural communities and (usually urban) centres of power and decision-making - creates spatial isolation which increases the transaction costs of governance. While rural and remote communities are not homogenous, the economic capacity of rural communities is also typically constrained in comparison to urban areas. ${ }^{15}$

Systemic issues, such as issues concerning biodiversity caused by climate change, and the need for habitat connectivity and control of invasive species to protect biodiversity, require coordinated action by landholders who operate diverse enterprises (with different incentives and concerns) and whose capacities vary. In general, coordinated action is impeded by fragmentation due to land titles and land use diversity. Homogenous farming landscapes are declining due to subdivision (including lifestyle farms) and ownership diversification (including Indigenous lands, corporate and international ownership). Coordinated action is further confounded by institutional fragmentation through an increasing number of private and public governance 'silos', and many laws and programs. ${ }^{16}$

13 Martin and Williams (2016), above n 10.

14 Bill Pritchard, Land of Discontent: The Dynamics of Change in Rural And Regional Australia (UNSW Press, 2000).

15 Vaughan Higgins and Stewart Lockie, 'Re-discovering the Social: Neo-Liberalism and Hybrid Practices of Governing in Rural Natural Resource Management' (2002) 18(4) Journal of Rural Studies 419.

16 Martin and Williams (2010), above $\mathrm{n} 9$. 
The reality of conditions faced by those living in rural areas raises difficult policy questions including:

1. To what degree is it reasonable or fair to expect landholders to privately fund public-good investment where there is no private benefit, without a public contribution to that work? This is a particularly difficult question when episodic factors like drought prevent otherwise responsible landholders from carrying out essential environmental works.

2. To what degree is it sensible and in the public interest to impose economically or physically infeasible requirements? This problem is particularly pronounced when farmlands are marginal, where abandonment or chronic incapacity will lead to no environmental work being conducted (other than at the full cost to the public purse).

'Public/private' allocation approaches to social problems, which may make sense when both public and private resources are available, ${ }^{17}$ do not work well when the public or private purse is empty. Nor do approaches work when they oblige farmers to take stewardship actions beyond their traditional obligations. Rural governance arrangements must find ways that transcend private boundaries to share the load of biodiversity protection, and to provide resources and incentives to encourage action.

\section{Changing Meta-Governance}

The discussion above suggests that Australia's strategy for making and implementing legal arrangements must become far more nuanced. We propose four meta-governance reforms, which combine different governance mechanisms to achieve a more coordinated and effective rural environmental governance regime. ${ }^{18}$ The degree of change we recommend is radical, but if the present system is not working then radical change must be entertained.

17 For example, David Pannell, Pannell Discussions No. 80: Public Benefits, Private Benefits: The Final Framework (Pannell Discussions, 19 June 2006), www.pannelldiscussions.net/2006/06/80public-benefits-private-benefits-the-final-framework/.

18 Louis Meuleman and Ingeborg Niestroy, 'Common but Differentiated Governance: A Metagovernance Approach to Make the SDGs Work’ (2015) 7(9) Sustainability 12295-321. 
1. A more systemic approach. Many rural natural resource governance problems are systemic in nature and laws need to reflect this to be more effective. This approach has three levels: $:^{19}$

a. A more sophisticated national approach to rural biodiversity protection and restoration that provides a comprehensive framework for governance. The approach needs to interweave biophysical and socioeconomic factors to address the implementation challenges. The approach should be coupled with ongoing performance reviews of governance to provide a 'roadmap' for continuing improvement in rural environmental governance including law reform.

b. Legal instruments need to more effectively address system protection and should have explicit implementation strategies, notably for whole-of-landscape action beyond individual farm boundaries. Often this will require interventions to align the socioeconomic context with the legal strategy in order to support change.

c. Governance is becoming less government centred, as citizen organisations and industry take an increasing role and as the limits to government power and capacity become more pronounced. ${ }^{20}$ Industry self-regulation and co-regulation are already significant in farming, in the form of buyer-chain environmental and other requirements, industry standards and codes, and market-based standards. ${ }^{21}$ Still lacking are a strategy to harness this potential, and integrity mechanisms to ensure that such schemes are not de facto unjustifiable deregulation.

2. Rural regulatory design and review processes. ${ }^{22}$ Current regulatory review is minimal and focused only on business cost. It does not address risks of implementation failure, nor of social spillovers. A more comprehensive approach is needed to:

19 For further details, see Paul Martin and Neil Gunningham, 'Improving Regulatory Arrangements for Sustainable Agriculture: Groundwater as an Illustration' (2014) 1(1) Australian Journal of Environmental Law 5; Mark Burgman et al, 'Designing Regulation for Conservation and Biosecurity' (2009) 13(1) Australasian Journal of Natural Resources Law and Policy 93.

20 C E Wilson, T H Morrison and J-A Everingham, 'Linking the "Meta-Governance" Imperative to Regional Governance in Resource Communities' (2017) 50 Journal of Rural Studies 188-97.

21 See Andrew Lawson, Farmers, Voluntary Stewardship Programs, and Collaborative Natural Resource Governance in Rural Australia (PhD thesis, University of New England, 2016).

22 Paul Martin et al, Developing a Good Regulatory Practice Model for Environmental Regulations Impacting on Farmers (Australian Farm Institute and Land and Water Australia, 2007). 
a. objectively review plans for implementation, including consideration of commitments from government to funding and other implementation requirements for the laws that they propose to create;

b. consider the likely outcome effectiveness and distributional effects of proposed laws, and canvass how possible inadequacies and perverse impacts will be addressed.

3. An investment model is needed for the rural environment. This in turn has two levels: ${ }^{23}$

a. Our estimate is that landscape protection and restoration requires approximately 2 per cent of GDP, ${ }^{24}$ and others would argue that far more is needed..$^{25}$ After extensive research we have been unable to identify how much is actually being invested and by whom. There is no institutional mechanism to coordinate potential streams of investment, nor to maximise that investment. Economic feasibility is fundamental to legal effectiveness, and the lack of an investment strategy for the environment suggests a fundamental weakness in Australia's governance efforts.

b. Investment is needed to support coordinated action by landholders, particularly when action goes beyond their site-specific legal responsibilities, if stewardship is to be effective. New projectspecific funding streams are possible, but legal and institutional arrangements are needed to maximise and organise these opportunities. Organisational structures, and issues of contract and securitisation, are representative of issues where better legal arrangements are needed. Other law reforms such as changes to taxation may be needed to encourage private collective investment.

23 Paul Martin and Kip Werren, 'The Use of Taxation Incentives to Create New Eco-Service Markets: Critical Issues' in Lin-Heng Lye and Janet E Milne (eds), Critical Issues in Environmental Taxation (Oxford University Press, 2009) Vol 7, 511; Paul Martin and Kip Werren, 'Discussion Paper: An Industry Plan for the Victorian Environment?' (Department of Sustainability and Environment, State Government of Victoria, 2009); Kip Werren, Utilising Taxation Incentives to Promote Private Sector Funded Conservation (PhD Thesis, University of Western Sydney, 2015).

24 Martin and Werren, above n 23.

25 Marty Sammon and Mark Thomson, Land Stewardship: Private Investor Needs For Land Stewardship Investment (Department of Sustainability and Environment, State Government of Victoria, 2003); The Virtual Consulting Group and Griffin NRM Pty Ltd, 'National Investment in Rural Landscapes: An Investment Scenario for NFF and ACF with the Assistance of LWRRDC' (Australian Conservation Foundation and National Farmers Federation with assistance from Land \& Water Resources Research \& Development Corporation, 2000). 
4. Negotiated regionalism. Bioregional planning is possible under the Environment Protection and Biodiversity Conservation Act, and could make a substantial contribution to improved biodiversity outcomes. From a socioeconomic perspective, this presents the opportunity to marry a science-based approach to a more community-based approach.

\section{Conclusion}

Australia has a national biodiversity strategy, ${ }^{26}$ and provides a national assessment of its performance under that strategy when reporting on implementation of its international commitments to biodiversity protection. ${ }^{27}$ On a regular basis, independent scientists publish the Australian State of Environment Report, a review of the biophysical status of the environment. Australia also has institutional arrangements to ensure that the welfare of rural communities and the sustainability of rural landscapes are protected. What Australia has not yet done is tie these elements together in a process of continuous improvement in the effectiveness of our legal arrangements for rural biodiversity protection. Similarly, Australia has a tradition of regulatory review, but it has not extended that process to properly take into account the implementation requirements and social justice implications of laws.

These are gaps in meta-governance which could be filled by an extension of existing rules and structures, potentially forming a basis for disciplined continuous improvement, based on sound empirical evidence of governance performance. Well-focused attention on the actual performance of legal arrangements, and the reasons for that performance, would be most likely to highlight the other issues we have discussed in this chapter, including the need for a viable investment base for sustainability, and the challenges of social justice embedded in the pursuit of this goal. Of all the possible changes that could improve the rural biodiversity outcomes for Australia, the most powerful would be reforming meta-governance in order to embed a process of empirically-based improvement in laws, other rules and institutions for implementation.

26 It is updated periodically; for the current strategy, see National Biodiversity Strategy Review Task Group, 'Australia's Biodiversity Conservation Strategy 2010-2030' (Natural Resource Management Ministerial Council, 2010).

27 Department of the Environment, 'Australia's Fifth National Report under the Convention on Biological Diversity' (Australian Government, 2014). 
This text is taken from New Directions for Law in Australia: Essays in Contemporary Law Reform, edited by Ron Levy, Molly O’Brien, Simon Rice, Pauline Ridge and Margaret Thornton, published 2017 by ANU Press, The Australian National University, Canberra, Australia. 